\title{
Editorial
}

\section{Disclosures of Coca-Cola funding: transparent or opaque?}

First published online 21 March 2018

In August 2015, in response to a New York Times article reporting on the Coca-Cola Company's funding of the Global Energy Balance Network ${ }^{(1)}$, the company's CEO Muhtar Kent declared a commitment to 'act with even more transparency ${ }^{\text {(2) }}$. They would achieve this in part by publishing on their website a list of partnerships, research activities $^{(3)}$ and Coca-Cola-funded scientific investigators ${ }^{(4)}$, to be updated every six months.

In their article in this issue of Public Health Nutrition $(P H N)$, Serôdio et al. ${ }^{(5)}$ evaluate efforts towards transparency on the part of both Coca-Cola and Coca-Cola-funded investigators. They use the Web of Science Core Collection database, which includes information from funding acknowledgements and competing interest statements. Their findings, in brief, show:

1. Reporting of conflicts of interest by Coca-Cola-funded investigators is incomplete. Serôdio et al. were unable to find any declared conflicts of interest from at least thirty-eight (17\%) of the 218 recipients of Coca-Cola funding included on Coca-Cola's transparency lists. Disclosure of funding from pharmaceutical companies for clinical trials is under-reported ${ }^{(6-8)}$; Serôdio et al.'s analysis demonstrates that the same occurs in public health nutrition research.

2. Coca-Cola's transparency lists of scientific investigators are incomplete. Of 331 articles identified from the Web of Science as having acknowledged funding from Coca-Cola, 128 (39\%) had no authors who were among the 218 listed on Coca-Cola's transparency lists. This incompleteness suggests that Coca-Cola has a more extensive influence on research activities than its transparency lists imply.

3. A leading topic of research in Coca-Cola-funded work was physical activity. Serôdio et al.'s structural topic modelling analysis of all articles with acknowledged Coca-Cola funding provides an empirical confirmation of suggestions that the company funds research that 'shifts attention' from sugary beverages to physical activity and energy balance as determinants of obesity ${ }^{(9)}$.

\section{The problem with incomplete disclosure}

The problem with incomplete disclosure, of course, is that readers are not given the complete information needed to critically assess an article fully. In a previous editorial, we discussed the problem of disclosed conflicts of interest
$(\mathrm{CoI})^{(10)}$. Our editorial focused on how CoI disclosures might affect readers' reactions to an article, and on the importance of considering non-financial CoI. A primary theme was that although disclosure is not a perfect system, it is all we have, and transparency remains and should remain the goal.

Serôdio et al. further the discussion by bringing attention to the problem of incomplete disclosure. Most medical and health journals have policies requiring some form of disclosure ${ }^{(11-13)}$. Thus, reasons for failing to disclose CoI, particularly financial ones, are unclear, although different CoI time windows across journals (requiring disclosure of financial relationships for $2 v .3$ years prior to the manuscript's submission, for example) is one potential source of ambiguity ${ }^{(11,12,14)}$.

Also unclear is what to do with an article when an undisclosed $\mathrm{CoI}$ is discovered. Rejection or retraction are possible outcomes in some journal policies ${ }^{(11,12)}$. Alternatively, guidelines from the Committee on Publication Ethics (COPE; of which $P H N$ is a member) suggest that, assuming the author 'supplies relevant details' when asked about an undisclosed CoI, the journal 'thank author but point out seriousness of omission', then 'publish correction to competing interest statement as required ${ }^{\text {(15) }}$. The tools we have to enforce or monitor enforcement of disclosure policies are clearly limited. We rely on our Editorial Board, reviewers and readers to call out undisclosed CoI when they encounter them ${ }^{(16)}$.

\section{The problem with incomplete transparency lists}

Coca-Cola's effort towards transparency is a step in the right direction. But the incompleteness of its transparency lists ends up giving us a limited view of the extent to which it influences the published, peer-reviewed literature. Authors of industry-funded studies, including systematic reviews and meta-analyses, are more likely to draw conclusions favourable to the industry funding them ${ }^{(17-21)}$ and there are ways to breech research integrity that the peer review process cannot easily identify ${ }^{(22)}$. But Serôdio et al.'s analysis demonstrates Coca-Cola's influence not on how research is conducted, but on what questions are being asked.

Ideally, the questions we ask in public health research are motivated by the desire to improve public health. The problem with research questions funded by Coca-Cola is 
that Coca-Cola is not primarily motivated to improve public health. By choosing to fund certain studies, CocaCola is tipping the scale towards the research questions it would like asked ${ }^{(23)}$, not necessarily the questions that need to be asked, and potentially overshadowing other equally if not more important work. In this way, Coca-Cola can become the driver of (or obstacle to) public health action simply by pouring resources on to a given question.

Partnering with industry is advantageous in an era when funding for research and community health programmes is limited. Coca-Cola has funded community programmes, programmes in low- and middle-income countries, and research ${ }^{(3,24)}$. But with an industry partnership comes the responsibility to weigh what will be gained against the potential cost. At a broader level, industry funding may come at a cost to the integrity of the research and public health decision-making processes ${ }^{(25)}$.

\section{Balancing transparency and libel chill}

An additional, noteworthy aspect of Serôdio et al.'s findings is the inclusion of the names of researchers as part of the research findings and discussion. Serôdio et al. name the fifteen investigators who published the most articles with acknowledged funding from Coca-Cola; use names to label the results of their network analysis of co-authorships of Coca-Cola-funded research; and refer by name to two publicized cases of investigators revealed to have undisclosed funding from Coca-Cola. The inclusion of names serves the purpose of firmly grounding the results and their implications in reality.

The decision to publish the names was well-considered. After consulting with the authors and The Nutrition Society, it was decided that moving forward was appropriate given the stringent peer review process, the additional, careful review by members of our Editorial Board and the resolution not to fall prey to 'libel chill'(26) . Also worth noting is that the investigators named were in fact among those who disclosed their funding and/or were included on Coca-Cola's transparency lists.

\section{But is that the best we can do?}

In a New York Times article ${ }^{(1)}$, Gregory Hand, the former dean of the West Virginia School of Public Health, is quoted as saying, 'As long as everybody is disclosing their potential conflicts and they're being managed appropriately, that's the best that you can do.' But first, as Serôdio et al. show, everybody is not disclosing their potential conflicts. Second, is that really the best we can do?

Gilmore and Capewell suggest 'radical funding models that allow corporations to fund research while protecting that research from their influence ${ }^{(27)}$. In the absence of any radical change in funding models, there are other things we can do. First, management of disclosures requires, at a minimum, the tools to track them easily. Dunn et al. ${ }^{(28)}$ describe the characteristics of an effective registry for recording CoI. Such a registry is similar in concept to the Open Payments database developed as a result of the Physician Payments Sunshine Act in the $\mathrm{USA}^{(29)}$. Given the potential influence of food and beverage companies, the same tool might be useful to monitor funding and CoI in public health and nutrition research.

With respect to what can be done in research, $P H N$ welcomes contributions that monitor the quality and transparency of scientific publications and the impact of CoI, with the objective of advancing science, providing an appropriate evidence base for action and encouraging debate. These might include, for example: (i) monitoring the disclosure policies of nutrition journals; (ii) determining the extent of undisclosed $\mathrm{CoI}$ in public health nutrition-related research; (iii) examining whether research findings differ according to amount of funding, or according to whether authors were directly or indirectly funded; and (iv) evaluating the influence of industry funding on the research topics being studied.

$P H N$ can also serve as a forum for academic debate. Recent publications in $J A M A$ and $B M J$ are examples of sharing the range of different viewpoints on $\mathrm{CoI}^{(30)}$ and on whether food industry should fund public health research $^{(27)}$. In the case of Coca-Cola (or other food industry) funded research, it would be useful to see the benefits and costs addressed point-by-point, as a way for us as a scientific community to identify common ground we all want to see improvements in public health, for example - and to identify where our priorities diverge.

As we have stated previously ${ }^{(10)}$, disclosure and transparency are necessary. But they are not by themselves sufficient to ensure the highest standards of research, both in terms of how it is conducted and what is being studied.

Marilyn Tseng

Editor-in-Chief

Joaquin Barnoya

Associate Editor

Salome Kruger

Carl Lachat

Stefanie Vandevijvere

Eduardo Villamor

Deputy Editors

Email: mtseng@calpoly.edu

\section{References}

1. O'Connor A (2015) Coca-Cola funds scientists who shift blame for obesity away from bad diets. The New York Times, 9 August 2015. https://well.blogs.nytimes.com/2015/08/09/ coca-cola-funds-scientists-who-shift-blame-for-obesity-awayfrom-bad-diets/ (accessed February 2018). 
2. Kent M (2015) 'We'll Do Better': Coca-Cola Vows to Improve Transparency. http://www.coca-colacompany.com/stories/welldo-better-coca-cola-vows-to-improve-transparency (accessed February 2018).

3. The Coca-Cola Company (2017) Our Actions and Way Forward. http://transparency.coca-colacompany.com (accessed February 2018).

4. The Coca-Cola Company (2017) List of Health Professionals and Scientific Experts. http://www.coca-colacompany.com/ transparency/list-of-health-professionals-and-scientific-experts (accessed February 2018).

5. Serôdio PM, McKee M \& Stuckler D (2018) Coca-Cola - a model of transparency in research partnerships? A network analysis of Coca-Cola's research funding (2008-2016). Public Health Nutr (Epublication ahead of print version).

6. Kesselheim AS, Wang B, Studdert DM et al. (2012) Conflict of interest reporting by authors involved in promotion of off-label drug use: an analysis of journal disclosures. PLOS Med 9, e1001280.

7. Rasmussen K, Schroll J, Gøtzsche PC et al. (2015) Underreporting of conflicts of interest among trialists: a crosssectional study. I $R$ Soc Med 108, 101-107.

8. Norris SL, Holmer HK, Ogden LA et al. (2012) Characteristics of physicians receiving large payments from pharmaceutical companies and the accuracy of their disclosures in publications: an observational study. BMC Med Ethics 13, 24.

9. Choi C (2015) APNewsBreak: Emails reveal Coke's role in anti-obesity group. AP News, 24 November 2015. http:// www.apnews.com/1fd235360ac94dcf893a87e3074a03a5/ apnewsbreak-emails-reveal-cokes-role-anti-obesity-group (accessed February 2018).

10. Tseng M, Hodge A, Lachat C et al. (2016) On the pitfalls of disclosure statements. Public Health Nutr 19, 383.

11. Shawwa K, Kallas R, Koujanian S et al. (2016) Requirements of clinical journals for authors' disclosure of financial and non-financial conflicts of interest: a cross sectional study. PLoS One 11, e0152301.

12. Khamis AM, Hakoum MB, Bou-Karroum L et al. (2017) Requirements of health policy and services journals for authors to disclose financial and non-financial conflicts of interest: a cross-sectional study. Health Res Policy Syst $\mathbf{1 5}, 80$.

13. Resnik DB, Konecny B \& Kissling GE (2017) Conflict of interest and funding disclosure policies of environmental, occupational, and public health journals. I Occup Environ Med 59, 28-33.

14. Fontanarosa P \& Bauchner H (2017) Conflict of interest and medical journals. JAMA 317, 1768-1771.

15. Committee on Publication Ethics (2013) What to do if a reader suspects undisclosed conflict of interest (CoI) in a published article. http://www.publicationethics.org/files/ COI\%20published.pdf (accessed February 2018).
16. Monteiro CA, Cannon G, Moubarac JC et al. (2018) Ultraprocessing. An odd 'appraisal'. Public Health Nutr 21, 497-501.

17. Lesser LI, Ebbeling CB, Goozner M et al. (2007) Relationship between funding source and conclusion among nutritionrelated scientific articles. PLOS Med 4, e5.

18. Bes-Rastrollo M, Schulze MB, Ruiz-Canela M et al. (2013) Financial conflicts of interest and reporting bias regarding the association between sugar-sweetened beverages and weight gain: a systematic review of systematic reviews. PLOS Med 10, e1001578.

19. Massougbodji J, Le Bodo Y, Fratu R et al. (2014) Reviews examining sugar-sweetened beverages and body weight: correlates of their quality and conclusions. Am J Clin Nutr 99, 1096-1104.

20. Mandrioli D, Kearns CE \& Bero LA (2016) Relationship between research outcomes and risk of bias, study sponsorship, and author financial conflicts of interest in reviews of the effects of artificially sweetened beverages on weight outcomes: a systematic review of reviews. PLoS One 11, e0162198.

21. Ludwig D (2018) Source of bias in sugar-sweetened beverage research: a systematic review. Public Health Nutr (In the Press)

22. Carlisle JB (2017) Data fabrication and other reasons for non-random sampling in 5087 randomised, controlled trials in anaesthetic and general medical journals. Anaesthesia 72, 944-952.

23. Sacks G, Swinburn BA, Cameron AJ et al. (2018) How food companies influence evidence and opinion - straight from the horse's mouth. Crit Public Health 28, 253-256.

24. The Coca-Cola Company (2012) Education. http://www. coca-colacompany.com/stories/education (accessed February 2018).

25. Fuller T, O'Connor A \& Richtel M (2017) In Asia's fattest country, nutritionists take money from food giants. New York Times, 23 December 2017. https://www.nytimes.com/ 2017/12/23/health/obesity-malaysia-nestle.html (accessed February 2018).

26. Persaud N, Ringer $\mathrm{T} \&$ \& Lemmens $\mathrm{T}$ (2014) How can journals respond to threats of libel litigation? PLoS Med 11, e1001615.

27. Aveyard P, Yach D, Gilmore AB et al. (2016) Should we welcome food industry funding of public health research? BMJ 353, i2161.

28. Dunn AG, Coiera E, Mandl KD et al. (2016) Conflict of interest disclosure in biomedical research: a review of current practices, biases, and the role of public registries in improving transparency. Res Integr Peer Rev 1, 1.

29. Centers for Medicare \& Medicaid Services (2018) Open Payments. http://www.cms.gov/OpenPayments/index.html (accessed February 2018).

30. Stead WW (2017) The complex and multifaceted aspects of conflicts of interest. JAMA 317, 1765-1767. 